\title{
Substrate metabolism, appetite and feeding behaviour under low and high energy turnover conditions in overweight women
}

\author{
Francesca L. Burton ${ }^{1}$, Dalia Malkova ${ }^{2}$, Muriel J. Caslake ${ }^{3}$ and Jason M. R. Gill ${ }^{1}$ \\ ${ }^{1}$ Integrative and Systems Biology, Faculty of Biomedical and Life Sciences, University of Glasgow, Glasgow G12 8QQ, UK \\ ${ }^{2}$ Division of Developmental Medicine, University of Glasgow, Glasgow G12 8QQ, UK \\ ${ }^{3}$ Section of Vascular Biochemistry, University of Glasgow, Glasgow G12 8QQ, UK
}

(Received 11 November 2009 - Revised 16 April 2010 - Accepted 19 April 2010 - First published online 22 June 2010)

The present study aimed to investigate whether substrate metabolism, appetite and feeding behaviour differed between high and low energy turnover conditions. Thirteen overweight premenopausal women completed two $1 \mathrm{~d}$ trials: low energy turnover (LET) and high energy turnover (HET), in a randomised, cross-over design. In LET, subjects consumed a test breakfast (49\% carbohydrate, $37 \%$ fat, $14 \%$ protein) calculated to maintain energy balance over a $6 \mathrm{~h}$ observation period, during which metabolic rate and substrate utilisation were measured and blood samples taken. Immediately following this an ad libitum buffet meal was provided. HET was identical to LET, except that subjects walked on a treadmill for $60 \mathrm{~min}$ at $50 \% \mathrm{~V}_{\mathrm{O} 2 \max }$ before the test breakfast, which was increased in size (by about $65 \%$ ) to replace the energy expended during the walk and maintain energy balance over the observation period. Postprandial fat balance (i.e. the difference between fat intake and oxidation) was lower and carbohydrate balance higher in HET compared with LET throughout the postprandial period $(P<0 \cdot 05$ for both). After the buffet meal, carbohydrate balance did not differ between trials but energy and fat balances were lower (by $0.28 \mathrm{MJ}$ and $11.6 \mathrm{~g}$, respectively) in HET compared with LET $(P<0.001$ for both). Carbohydrate balance immediately before the buffet meal correlated negatively with buffet energy intake $(r-0.49)$ and postprandial acylated ghrelin responses $(r-0.48)$, and positively with postprandial glucose responses $(r 0 \cdot 49)$. These findings demonstrate that HET resulted in a more positive carbohydrate balance than LET, which associated with lower subsequent energy intake. This may have implications for the regulation of body weight.

Energy turnover: Appetite: Carbohydrate balance: Fat balance

Individuals who undertake high levels of physical activity maintain energy balance and stable body weights more effectively than their sedentary peers ${ }^{(1,2)}$ and long-term maintenance of weight loss in the formerly obese is facilitated by high physical activity ${ }^{(3,4)}$. Thus, over the long term, the interaction between energy intake and energy expenditure for the regulation of energy balance appears to differ between high energy turnover (i.e. high physical activity) and low energy turnover (i.e. low physical activity) conditions. As maintenance of energy balance and body weight over the long term is the culmination of repeated short-term interactions between energy expenditure and energy intake, short-term metabolic studies can help understanding of the physiological and behavioural mechanisms involved in the regulation of energy balance under high or low energy turnover conditions.

A number of reports have evaluated the effects of an exercise session on subsequent energy metabolism, reporting postexercise increases in fat oxidation immediately ${ }^{(5,6)}$ and for up to $24 \mathrm{~h}^{(7,8)}$, although this is not unequivocal ${ }^{(9)}$. This shift in metabolism towards fat oxidation may be important for body-weight regulation, as high levels of fat oxidation, measured either at rest in the fasted state $e^{(10,11)}$ or over
$24 \mathrm{~h}^{(12)}$ have been shown to be protective against subsequent long-term weight gain, independent of metabolic rate. The acute effects of an exercise session on subsequent appetite regulation and feeding behaviour have also been investigated. Studies measuring food intake have fairly consistently shown that energy intake remains unchanged immediately following an exercise session ${ }^{(13-16)}$ although relative energy intake i.e. energy intake after accounting for the additional energy expended during exercise - is generally lower ${ }^{(15,17)}$. Over more prolonged periods of time, evidence suggests that some degree of dietary compensation for the exercise-induced energy expenditure may occur, at least in women ${ }^{(18)}$. Exercise may also alter macronutrient preferences, although again the literature is equivocal with some showing fat ${ }^{(19)}$ and others carbohydrate ${ }^{(20,21)}$ to be preferentially consumed after exercise, whilst others observe no difference in macronutrient consumption $^{(14,16)}$. Exercise-induced changes in appetite and feeding behaviour may, in part, be explained by fluctuations in appetite hormones, such as ghrelin. Although studies have consistently shown no change in total ghrelin in response to exercise $^{(17,22-24)}$, a reduction in acylated ghrelin has been observed $^{(25-28)}$. However, the implications of this for appetite

Abbreviation: VAS, visual analogue scale.

* Corresponding author: Dr Jason M. R. Gill, fax +44 141 3305481, email j.gill@bio.gla.ac.uk 
regulation and subsequent energy intake are not clear and require further investigation.

In the acute studies described above, the energy expended during the exercise session was not replaced post-exercise, making it difficult to disentangle the separate effects of exercise $v$. its associated energy deficit on metabolism, appetite regulation and feeding behaviour. It, therefore, remains unclear how exercise might affect metabolism and appetite when the associated energy deficit is replaced and energy balance maintained, a state that is representative of regular exercisers who maintain a stable body weight. Improved sensitivity of appetite regulation and the enhanced ability to adjust energy intake in response to prior foods eaten has been reported in those who are regularly physically active ${ }^{(29,30)}$; however, it is currently unclear whether this increased sensitivity of appetite occurs acutely in response to recent exercise. We have previously shown that fasting and postprandial fat oxidation is higher on the day following an exercise session without an associated energy deficit (high energy turnover energy balance) than following a day when no exercise was performed (low energy turnover energy balance $)^{(31)}$, but effects on appetite and feeding behaviour are not known, nor are the effects on metabolism during the several hours immediately post-exercise. The aim of the present study, therefore, is to determine whether differences exist in energy metabolism, appetite and feeding behaviour over the course of a day between high energy turnover and low energy turnover energy balance conditions.

\section{Methods}

\section{Subjects}

A total of thirteen premenopausal women were recruited to the present study. Their physical characteristics were age 32 (SD 8) years, BMI 27.5 (SD 1.1$) \mathrm{kg} / \mathrm{m}^{2}$, waist circumference $87.1(\mathrm{SD} 6.2) \mathrm{cm}$ and maximal oxygen uptake $\left(\mathrm{V}_{\mathrm{O} 2 \max }\right) 34.7$ (SD 5.8) $\mathrm{ml} / \mathrm{kg}$ per min. All of the women were apparently healthy non-smokers, with no known history of CVD or diabetes. None was taking any medication thought to interfere with lipid or energy substrate metabolism. The present study was conducted according to the guidelines laid down in the Declaration of Helsinki and all procedures involving human subjects/patients were approved by the Faculty of Biomedical and Life Sciences Ethics Committee at the University of Glasgow (Glasgow, UK). Each subject gave written informed consent before participation.

\section{Experimental design}

After preliminary testing, each subject completed two separate $1 \mathrm{~d}$ trials: energy balance with low energy turnover (low energy turnover) and energy balance with high energy turnover (high energy turnover). Trials were performed in a randomised design and completed at an interval of 4 weeks to avoid potential confounding effects of the menstrual cycle. An overview of the study protocol is shown in Fig. 1. For $3 \mathrm{~d}$ before each experimental trial, subjects were instructed to avoid alcohol and all exercise, other than activities of daily living. During the $3 \mathrm{~d}$ preceding their first trial, subjects recorded all of the food and drink that they consumed and were instructed to replicate this diet for the $3 \mathrm{~d}$ preceding their second experimental trial.

\section{Preliminary sessions}

A four-stage preliminary submaximal treadmill test ${ }^{(32)}$ was completed before the first experimental trial to estimate $\mathrm{V}_{\mathrm{O} \text { max }}$ and to calculate the speed and gradient that was required to elicit an intensity of $50 \% \mathrm{~V}_{\mathrm{O} 2 \max }$, the intensity that was used for the exercise in the high energy turnover trial.

Before the first experimental trial, subjects attended the metabolic suite having fasted overnight for at least $12 \mathrm{~h}$ for measurement of RMR. For this, and both experimental trials, subjects travelled to the laboratory using motorised transport to minimise physical activity before arrival. After $20 \mathrm{~min}$ of rest lying supine on a couch, metabolic rate was determined by indirect calorimetry using a ventilated hood (Deltatrac Metabolic Monitor; Datex Engstrom, Sidcup, Kent, UK). Expired air measurements were collected over $25 \mathrm{~min}$ and the mean value for the final $20 \mathrm{~min}$ was used to calculate RMR.

During the preliminary phase, individual subjects were also asked to complete a questionnaire providing details of: (i) foods they did not like; (ii) specific dietary requirements, for example, vegetarian; and (iii) all food allergies.
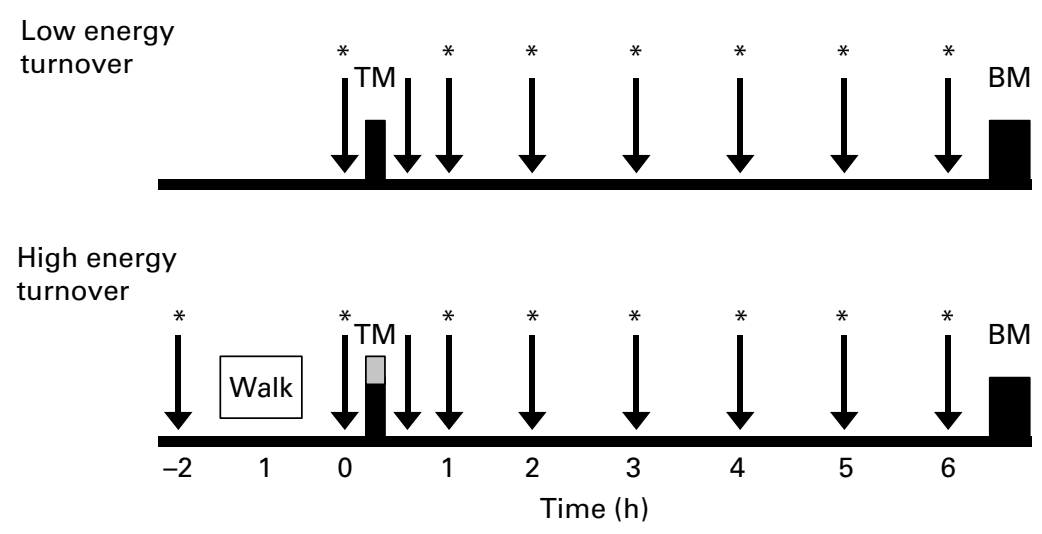

Fig. 1. Study design. Subjects completed two separate trials: low energy turnover and high energy turnover. In the high energy turnover trial, the net energy expenditure of exercise was replaced $(\square)$ at the test meal (TM). Regular blood samples and appetite questionnaires $(\downarrow)$ and expired air measurements $\left({ }^{*}\right)$ were collected. The buffet meal (BM) was completed $6.5 \mathrm{~h}$ after the test meal. 
This information was used to ensure that foods provided in the ad libitum buffet meal were suitable for subjects to consume.

\section{Low energy turnover trial}

Subjects attended the metabolic suite at 10.00 hours having fasted from 20.00 hours the evening before. Following a $10 \mathrm{~min}$ rest lying on a couch, a $25 \mathrm{~min}$ fasting expired air sample was collected (Deltatrac Metabolic Monitor; Datex Engstrom). A cannula was introduced into an antecubital vein, and after a $10 \mathrm{~min}$ interval, a fasting blood sample was taken $(0 \mathrm{~h}$ on Fig. 1), on completion of which a $10 \mathrm{~cm}$ visual analogue scale (VAS) questionnaire was used to rate their hunger, satiety, fullness, prospective food consumption and desire to eat ${ }^{(33)}$.

Once fasting measurements were made, the test breakfast was provided, the energy content of which was based on their expected energy expenditure during the $6 \mathrm{~h}$ observation period and designed to maintain energy balance. Energy content was individually calculated using RMR (in $\mathrm{kJ} / \mathrm{h}$ ) $\times$ $6 \times 1 \cdot 2$, where 1.2 represents an activity level of an individual who is chair or bed bound ${ }^{(34)}$. The meal comprised a bagel, polyunsaturated fat margarine and a meal-replacement drink (Complan; Complan Foods Ltd, London, UK) made with whole milk, and in total provided $49 \%$ of energy as carbohydrate, $37 \%$ as fat and $14 \%$ as protein. On completion of the meal, subjects underwent a $6 \mathrm{~h}$ postprandial observation period, during which regular blood samples and VAS appetite questionnaires were completed at $0 \cdot 5,1,2,3,4,5$ and $6 \mathrm{~h}$ after the test meal. Expired air measurements were made during the $15 \mathrm{~min}$ preceding the $1,2,3,4,5$ and $6 \mathrm{~h}$ blood samples. At $30 \mathrm{~min}$ after the final blood sample was collected $(6.5 \mathrm{~h}$ after the test meal), subjects were provided with a buffet meal, which is described below. During both the test meal and buffet meal, subjects completed VAS food palatability questionnaires rating the meals' appeal, smell, taste, aftertaste and palatability. Water was provided ad libitum during the postprandial period in the first trial with the volume and pattern repeated during the subsequent trial.

\section{High energy turnover trial}

Subjects attended the metabolic suite at 08.00 hours having fasted from 20.00 hours the previous evening. Fasting measurements were made $(-2 \mathrm{~h}$ on Fig. 1) as described for the low energy turnover trial before subjects completed a 60 min treadmill walk at $50 \% \mathrm{~V}_{\mathrm{O} 2 \max }$. At rest before the walk, at $15 \mathrm{~min}$ intervals during the walk and for $10 \mathrm{~min}$ after completion of the walk expired air samples were collected in Douglas bags for the determination of oxygen uptake and carbon dioxide production. Heart rate and rate of perceived exertion $^{(35)}$ were recorded at $15 \mathrm{~min}$ intervals during the walk. Water was provided ad libitum during and after the walk. On completion of the walk, subjects were allowed to shower and change before fasting post-exercise $(0 \mathrm{~h}$ on Fig. 1) expired air and blood samples and appetite questionnaires were repeated. Subjects were then provided with a test meal with the same composition as that consumed in the low energy turnover trial, but the energy content provided was RMR (in $\mathrm{kJ} / \mathrm{h}$ ) $\times 6 \times 1.2$ plus $107 \%$ of the net energy expenditure of the treadmill walk, to ensure that energy balance status post-breakfast was the same as in the low energy turnover trial. We replaced $107 \%$, rather than $100 \%$, of the energy during exercise at breakfast to account for the elevated metabolic rate during recovery from exercise which is typically in the order of $2-7 \%$ of the exerciseinduced energy expenditure ${ }^{(36-38)}$. After the test meal, a $6 \mathrm{~h}$ postprandial observation period and buffet meal were completed as described for the low energy turnover trial and food palatability questionnaires were collected following both meals.

\section{Ad libitum buffet meal}

Exactly the same buffet meal was provided in both trials with a variety of foods offered, including cheese and tomato pasta bake, salad and salad dressing, bread, butter, fruit cocktail, chocolate cake and cream. Overall, $46 \%$ of the energy in the foods provided was carbohydrate, $44 \%$ was fat and $10 \%$ was protein. All foods were individually weighed and presented to the subject in quantities in excess of expected consumption and in a way that avoided any effect of portion size on typical feeding behaviour. Meals were consumed in isolation to avoid the impact of other people on food consumption $^{(39)}$. Subjects were asked to eat until they reached their normal degree of satiation and $30 \mathrm{~min}$ was allowed for the meal, during which time no water was allowed. The weight of food consumed was calculated by subtracting the amount of food left from the original amount provided, the energy and nutrient content of which was determined using the food manufacturers' labels and a dietary analysis program (CompEat version 5; Nutrition Systems, Grantham, Lincs, UK). Subjects were blinded to the purpose of the buffet meal (i.e. measuring food intake), and were instead advised that the aim was to investigate the effects of exercise on markers of food palatability. This was done to reduce the potential bias that can occur if a person is consciously aware that food consumption is being monitored, as eating patterns and behaviour can be affected by a number of emotional and cognitive beliefs and restraints, especially with regards to the volume of food that is consumed and types of food that are perceived 'good or bad'(39).

\section{Blood analysis}

Blood samples were collected into K-EDTA tubes and placed on ice. All samples were separated within $15 \mathrm{~min}$ of collection and stored at $-80^{\circ} \mathrm{C}$ until analysis. Before centrifugation, $1.98 \mathrm{ml}$ blood was extracted and treated with $p$-hydroxymercuribenzoic, centrifuged, and added to $1 \mathrm{M}$-hydrochloric acid solution in preparation for acylated ghrelin analysis. Plasma TAG, glucose and NEFA concentrations were determined by enzymic colourimetric methods using commercially available kits (Roche Diagnostics GmbH, Mannheim, Germany and Randox Laboratories Ltd, Crumlin, Co. Antrim, UK). Insulin and acylated ghrelin were determined using commercially available ELISA (Mercodia AB, Upsala, Sweden; Phoenix Europe GmbH, Karlsruhe, Germany and SPI-BIO, Montigny Le Bretonneux, France). All samples for each subject were analysed in a single analyser run. CV were $<3.1 \%$ for all non-ELISA assays, $3.9 \%$ for the insulin ELISA and $5.9 \%$ for the acylated ghrelin ELISA. 


\section{Statistical analysis}

Energy expenditure and energy substrate utilisation were calculated using indirect calorimetry ${ }^{(40)}$. For these calculations urinary $\mathrm{N}$ excretion was assumed to be $0.11 \mathrm{mg} / \mathrm{kg}$ per min throughout each trial, based on data from previous studies in the literature ${ }^{(41,42)}$. We consider this assumption to be justified, as data from previous studies have demonstrated that exercise with similar energy expenditures to the exercise intervention used in the present study, either with or without an energy deficit, does not influence postprandial protein oxidation rates ${ }^{(5,39,43)}$. The total area under the $6 \mathrm{~h}$ variable $v$. time curves (AUC), divided by the duration of the observation period $(6 \mathrm{~h})$, i.e. the time-averaged AUC, were used as summary measures of the postprandial responses. Cumulative energy and energy substrate balances were calculated by summing the AUC for individual time periods throughout each experimental trial.

Data were analysed using Statistica (version 6.0; StatSoft Inc., Tulsa, OK, USA) and Minitab (version 13.1; Minitab Inc., State College, PA, USA). Before any statistical analysis, all data were tested for normality using the Anderson-Darling normality test. Only acylated ghrelin data were found not to display a normal distribution and thus these values were normalised by logarithmic transformation (base 10) before any further statistical analysis (prior units $\mathrm{pg} / \mathrm{ml}$ ). Differences between trials for measurements made in the fasted state and summary postprandial responses were compared using paired-sample $t$ tests with differences over time for both trials calculated using two-way ANOVA with repeated measures for trial and time. Post hoc Tukey tests were used to identify where differences lay. Relationships between variables were assessed using Pearson product-moment correlations. Statistical significance was accepted at the $P<0.05$ level and data are presented as mean values with their standard errors unless otherwise stated.

\section{Results}

\section{Responses during treadmill walk}

Subjects walked for $1 \mathrm{~h}$ at a speed of $5.5($ SEM $0 \cdot 1) \mathrm{km} / \mathrm{h}$ up a gradient of 2.4 (SEM 0.6) \%. All subjects completed the walk without difficulty, rating the exercise as 'light' $(11 \cdot 1$ (SEM 0.3)) on the Borg scale of 6-20 ${ }^{(35)}$. Mean $\mathrm{V}_{\mathrm{O} 2}$ during the walk was 16.6 (SEM 0.7) $\mathrm{ml} / \mathrm{kg}$ per min (equivalent to $47 \%$ $\mathrm{V}_{\mathrm{O} 2 \max }$ ) and mean heart rate was 123 (SEM 2) beats/min. Net energy expenditure of the walk was 1.18 (SEM 0.07) MJ, and there was an additional net energy expenditure of 0.07 (SEM 0.02) MJ during recovery following exercise before energy expenditure returned to baseline. Net fat and carbohydrate oxidation during the walk was 22.3 (SEM 1.4) $\mathrm{g}$ and $18 \cdot 1$ (SEM 3.3) g, respectively.

\section{Energy and substrate utilisation in the fasted state}

In the low energy turnover trial, a fasting expired air sample was collected immediately before breakfast $(0 \mathrm{~h})$, and in the high energy turnover trial fasting expired air samples were collected pre-exercise $(-2 \mathrm{~h})$ and post-exercise $(0 \mathrm{~h})$. Fasting energy expenditure was not different between trials (low energy turnover, $251.3($ SEM $6 \cdot 5$ ) $\mathrm{kJ} / \mathrm{h}$; high energy turnover pre-exercise, $251.5($ SEM 6.3$) \mathrm{kJ} / \mathrm{h} ; P=0.976)$ or within the high energy turnover trial itself (high energy turnover postexercise, $253.5($ SEM 6.6$) \mathrm{kJ} / \mathrm{h} ; P=0.583$ ) and there was also no difference between low energy turnover fasting and high energy turnover pre-exercise fat oxidation rates (low energy turnover, 3.73 (SEM 0.37) $\mathrm{g} / \mathrm{h}$; high energy turnover preexercise, $3.45($ SEM 0.32$) \mathrm{g} / \mathrm{h} ; P=0.407)$. Post-exercise fat oxidation (4.25 (SEM 0.26) g/h) was, however, significantly higher than pre-exercise in the high energy turnover trial $(P=0.007)$. Post-exercise carbohydrate oxidation was lower, compared with pre-exercise, in the high energy turnover trial (post-exercise, 2.09 (SEM 0.65) $\mathrm{g} / \mathrm{h}$; pre-exercise, 3.79 (SEM 0.68$) \mathrm{g} / \mathrm{h} ; P=0.023$ ) but there was no difference in low energy turnover fasting carbohydrate oxidation (3.12 (SEM 0.68) $\mathrm{g} / \mathrm{h}$ ) compared with either high energy turnover pre-exercise $(P=0.386)$ or post-exercise $(P=0.176)$ values.

\section{Energy and substrate balances}

Energy intake at breakfast was 1.94 (SEM 0.07) MJ in the low energy turnover trial and $3 \cdot 20$ (SEM 0.16) MJ in the high energy turnover trial. Total energy expenditure during the $6 \mathrm{~h}$ postprandial observation period was slightly higher in the high energy turnover trial (1.55 (SEM 0.05) MJ) than the low energy turnover trial (1.47 (SEM 0.04) MJ; $P=0.008$ ). This small difference is likely to reflect a greater thermic effect of food in the high energy turnover trial due to the larger energy intake at breakfast. However, there were no significant differences between trials in fat (low energy turnover, 18.7 (SEM 1.6) g; high energy turnover, 20.1 (SEM 1.5) g; $P=0.350$ ) or carbohydrate (low energy turnover, 26.5 (SEM 0.35) g; high energy turnover, 28.9 (SEM 3.5) g; $P=0.480)$ oxidation over this period.

Cumulative energy, fat and carbohydrate balances during each trial are shown in Fig. 2. By design, cumulative energy balance did not differ between trials over the course of the day, before the buffet meal. Immediately before the buffet meal, energy balance (relative to the start of the trial) was -0.16 (SEM 0.05) MJ in the low energy turnover trial and -0.18 (SEM 0.04) MJ in the high energy turnover trial $(P=0 \cdot 50)$. However, in the low energy turnover trial this was achieved by expending $2 \cdot 10$ (SEM 0.05) MJ of energy over the entire observation period (i.e. from $-2 \mathrm{~h}$ to $6 \mathrm{~h}$ on Fig. 1) and consuming 1.94 (SEM 0.07) MJ, whereas in the high energy turnover trial, this was achieved by expending 3.39 (SEM 0.12) MJ and consuming 3.20 (SEM 0.16) MJ. Thus, in the high energy turnover trial, energy balance was the same as in the low energy turnover trial, but energy turnover was about $60 \%$ greater. Energy intake in the buffet meal tended to be lower (by about $7 \%$ ) in the high energy turnover trial, although this did not achieve statistical significance (low energy turnover, 3.77 (SEM 0.16) MJ; high energy turnover, 3.51 (SEM 0.16) MJ; $P=0 \cdot 103$ ). However, on completion of the buffet meal cumulative energy balance was significantly lower (by about $8 \%$ ) in the high energy turnover trial (3.41 (SEM 0.16) v. 3.13 (SEM 0.15) MJ for the low and high energy turnover trials, respectively; $P<0.001$ ).

Postprandial cumulative fat balance was lower throughout the day in the high energy turnover trial $(P<0.05$ at all time points) and remained lower after the buffet meal (low energy turnover, 17.7 (SEM 3.1) g; high energy turnover 

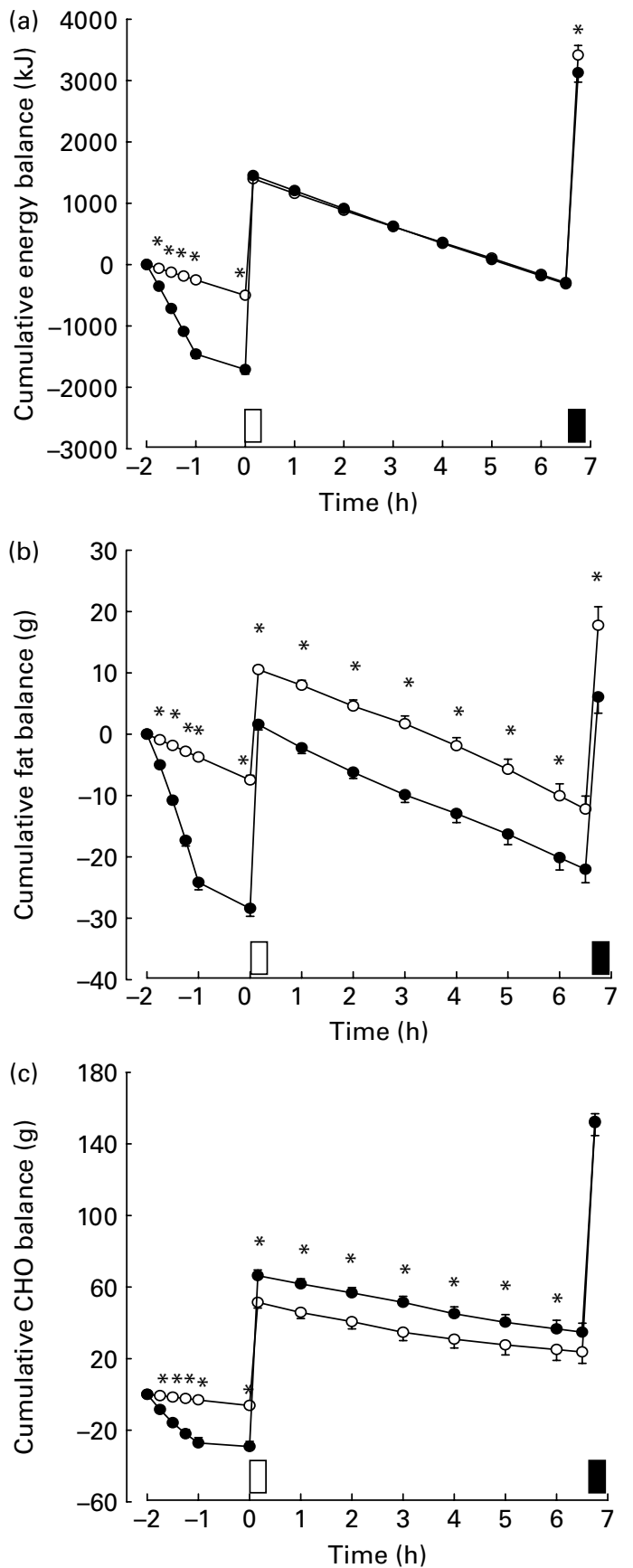

Fig. 2. Cumulative energy balance (a), cumulative fat balance (b) and cumulative carbohydrate $(\mathrm{CHO})$ balance (c) during the low energy turnover $(\mathrm{O})$ and high energy turnover $(\bullet)$ trials. Times at which the test meal $(\square)$ and buffet meal (घ) were provided are shown. Values are means, with standard errors represented by vertical bars. * Mean values were significantly different between trials $(P<0.001)$.

6.1 (SEM 2.7) g; $P<0.001$ ), although fat intake in the buffet meal did not differ between trials (low energy turnover, 31.0 (SEM 1.9) g; high energy turnover, 29.1 (SEM 1.3) g; $P=0 \cdot 210)$. Postprandial carbohydrate balance was higher over the course of the day in the high energy turnover trial before the buffet meal ( $P<0.05$ at all time points), but carbohydrate intake in the buffet tended to be lower (by about $8 \%$ ) in the high energy turnover trial (low energy turnover,
128.8 (SEM 5.9) g; high energy turnover, 118.7 (SEM 6.7) g; $P=0.082$ ), resulting in no difference in cumulative carbohydrate balance between trials after the buffet was completed (low energy turnover, 151.8 (SEM 7.2) g; high energy turnover, 152.5 (SEM 4.4) g; $P=1.000$ ). Protein intake at the buffet meal did not differ significantly between trials (low energy turnover, 29.2 (SEM 1.3) g; high energy turnover, 27.4 (SEM 1.9) $\mathrm{g} ; P=0 \cdot 204)$.

\section{Acylated ghrelin concentrations}

Due to technical problems, acylated ghrelin concentrations were not measured in two subjects; thus data are reported for eleven subjects. Log acylated ghrelin concentrations measured in the fasted state, $1 \mathrm{~h}$ following the walk, in the high energy turnover trial were significantly lower than values measured in the fasted state in the low energy turnover trial (low energy turnover, 1.94 (SEM 0.07); high energy turnover, 1.83 (SEM 0.07), $P=0.01$; median values before transformation: low energy turnover, $92.6 \mathrm{pg} / \mathrm{ml}$; high energy turnover, $65.7 \mathrm{pg} / \mathrm{ml}$ ). In addition, the postprandial log acylated ghrelin response was significantly lower in the high energy turnover trial than in the low energy turnover trial (low energy turnover, 1.90 (SEM 0.06); high energy turnover trial, 1.80 (SEM 0.06), $P=0.04$; median values before transformation: low energy turnover, $82.7 \mathrm{pg} / \mathrm{ml}$; high energy turnover, $65 \cdot 2 \mathrm{pg} / \mathrm{ml}$ ) (Fig. 3).

\section{Plasma metabolic variables}

In the low energy turnover trial, a single blood sample, immediately before breakfast $(0 \mathrm{~h})$, was taken in the fasted state, and in the high energy turnover trial blood samples were taken pre-exercise $(-2 \mathrm{~h})$ and post-exercise $(0 \mathrm{~h})$ in the fasted state. Data from the analysis of these samples are presented in Table 1. There were no significant differences between the pre-exercise value in the high energy turnover

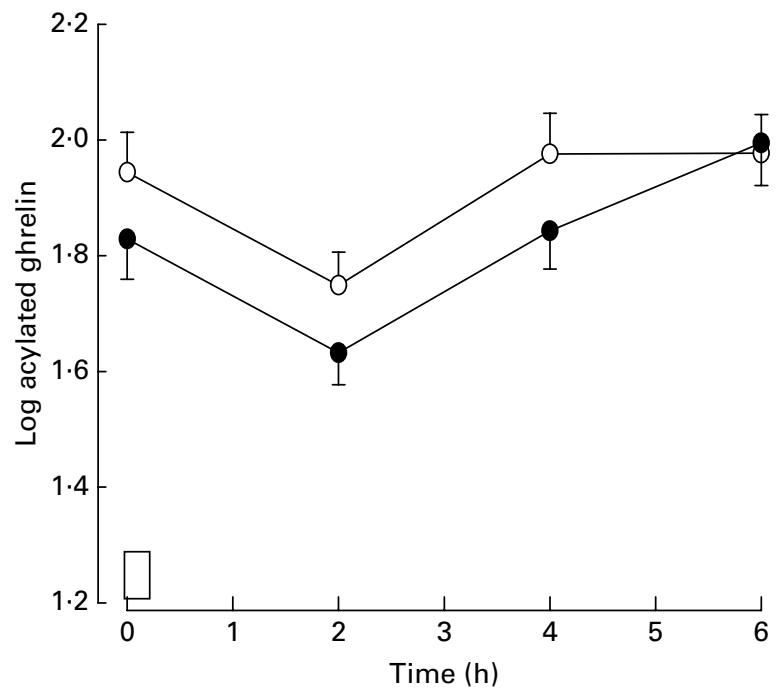

Fig. 3. Plasma log acylated ghrelin response during the low energy turnover $(\bigcirc)$ and high energy turnover $(\bullet)$ trials. The time at which the test meal $(\square)$ was provided is shown. Values are means, with standard errors represented by vertical bars. 
Table 1. Plasma metabolic variables in the fasted state $(n 13)$ (Mean values with their standard errors)

\begin{tabular}{|c|c|c|c|c|c|c|}
\hline & \multicolumn{2}{|c|}{$\begin{array}{l}\text { Low energy } \\
\text { turnover }\end{array}$} & \multicolumn{2}{|c|}{$\begin{array}{l}\text { High energy } \\
\text { turnover: } \\
\text { pre-exercise }\end{array}$} & \multicolumn{2}{|c|}{$\begin{array}{l}\text { High energy } \\
\text { turnover: } \\
\text { post-exercise }\end{array}$} \\
\hline & Mean & SEM & Mean & SEM & Mean & SEM \\
\hline TAG (mmol/l) & 0.70 & 0.05 & $0.82^{\star}$ & 0.09 & $0.71 \dagger$ & \\
\hline NEFA (mmol/l) & 0.59 & 0.05 & 0.58 & 0.05 & $0 \cdot 79^{\star} \dagger$ & 0.04 \\
\hline Glucose (mmol/l) & 4.89 & 0.05 & 4.99 & 0.13 & $4 \cdot 81$ & 0.08 \\
\hline Insulin (mU/l) & 3.82 & 0.42 & $4 \cdot 36$ & 0.52 & $3.29 \dagger$ & 0.48 \\
\hline
\end{tabular}

* Mean value was significantly different from that in the low energy turnover condition $(P<0.05)$.

† Mean value was significantly different from that pre-exercise (high energy turnover) $(P<0.05)$.

trial and the fasting value in the low energy turnover trial for any of these variables except for TAG concentrations, which were $17 \%$ higher in the high compared with the low energy turnover trial $(P=0 \cdot 048)$. Compared with fasting values in the low energy turnover trial, post-exercise NEFA concentrations in high energy turnover were $34 \%$ higher $(P=0 \cdot 011)$. Comparisons within the high energy turnover trial itself revealed post-exercise TAG concentrations $13 \%$ lower than pre-exercise values $(P<0 \cdot 001)$ whilst NEFA concentrations were $36 \%$ higher $(P=0.002)$. Glucose concentrations did not change post-exercise; however, insulin concentrations were $25 \%$ lower post-exercise compared with pre-exercise $(P=0 \cdot 019)$.

Summary measures of postprandial responses are given in Table 2 and the postprandial responses for TAG, NEFA, glucose and insulin are shown in Fig. 4. The postprandial NEFA response was $14 \%$ lower $(P=0.009)$ and postprandial glucose and insulin responses were $7 \%(P=0.023)$ and $62 \%$ $(P=0.002)$ higher, respectively, in the high energy turnover trial compared with the low energy turnover trial. There was no significant difference in the postprandial TAG response between trials.

\section{Subjective ratings of appetite}

There were no significant differences in subjective ratings of appetite over the course of the postprandial observation period between the two trials. Time-averaged postprandial appetite ratings are shown in Table 3 .

Table 2. Time-averaged postprandial area under the curve values for plasma metabolic variables $(n 13)$

(Mean values with their standard errors)

\begin{tabular}{lrrrrrr}
\hline & \multicolumn{2}{c}{$\begin{array}{c}\text { Low energy } \\
\text { turnover }\end{array}$} & & \multicolumn{2}{c}{$\begin{array}{c}\text { High energy } \\
\text { turnover }\end{array}$} \\
\cline { 2 - 3 } & Mean & SEM & & Mean & SEM & $P$ \\
\hline TAG (mmol/l) & 0.74 & 0.05 & & 0.79 & 0.06 & 0.145 \\
NEFA (mmol/l) & 0.37 & 0.02 & & 0.32 & 0.02 & 0.009 \\
Glucose $(\mathrm{mmol} / \mathrm{l})$ & 5.04 & 0.15 & & 5.38 & 0.10 & 0.023 \\
Insulin $(\mathrm{mU} / \mathrm{l})$ & 12.69 & 1.45 & & 20.49 & 1.97 & 0.002 \\
\hline
\end{tabular}

\section{Relationships between variables}

Energy and carbohydrate intakes at the buffet meal correlated positively with total carbohydrate oxidation over the postprandial observation period (energy intake $v$. carbohydrate oxidation: $r$ 0.42, $P=0.03$; carbohydrate intake $v$. carbohydrate oxidation: $r 0.52, P=0.007)$ and negatively with total fat oxidation over the postprandial period (energy intake $v$. fat oxidation: $r-0.39, P=0.049$; carbohydrate intake $v$. fat oxidation: $r-0.42, P=0.032$ ). There was a significant negative correlation between energy intake at the meal and carbohydrate balance measured just before the buffet meal $(r-0.49 ; P=0.01 ;$ Fig. 5$)$ and a reciprocal positive correlation between energy intake and fat balance measured just before the meal $(r 0.48 ; P=0.01)$. However, energy intake was not associated with energy balance immediately before the meal $(r-0 \cdot 17 ; P=0 \cdot 41)$. Furthermore, carbohydrate intake was negatively associated with carbohydrate balance before the buffet meal $(r-0.55 ; P=0.004)$, whilst there was no relationship observed between fat balance and fat intake $(r \quad 0.16 ; P=0.43)$. Carbohydrate balance just before the buffet meal correlated significantly positively with the plasma glucose response $(r 0.49 ; P=0.01)$ and negatively with the $\log$ acylated ghrelin response $(r-0.48$; $P=0.02$ ) at the same time point (Fig. 5). In addition, plasma glucose responses correlated negatively with the log acylated ghrelin response $(r-0.48 ; P=0.02 ;$ Fig. 5). There was a tendency for a negative correlation between glucose response and energy intake at the buffet meal which did not quite achieve statistical significance $(r-0.36 ; P=0.068)$.

\section{Discussion}

The main finding of the present study is that high turnover energy balance influences metabolism differently from low energy turnover energy balance. Although energy balance status between these two conditions was identical over the $6.5 \mathrm{~h}$ postprandial observation period, fat balance was significantly lower and, reciprocally, carbohydrate balance was higher throughout the high energy turnover trial compared with the low energy turnover trial. On completion of an ad libitum buffet meal at the end of the day, energy balance was about $280 \mathrm{~kJ}$ more negative in the high energy turnover trial and energy intake at the buffet meal correlated strongly with carbohydrate balance immediately before the meal. In addition, circulating concentrations of acylated ghrelin which stimulates appetite - were significantly lower over the course of the high energy turnover trial, and acylated ghrelin concentrations correlated negatively with carbohydrate balance. Thus, the present data imply that when exercise is performed and the energy expended is immediately replaced, carbohydrate balance is more positive than if exercise was not performed and that this is associated with reduced energy intake at the following meal.

The present findings - i.e. that high energy turnover energy balance led to a more positive carbohydrate balance - could conceivably have implications for the long-term regulation of body weight. Pannacciulli et al. ${ }^{(44)}$ reported that $24 \mathrm{~h}$ carbohydrate balance, measured in a respiratory chamber, was inversely associated with daily energy intake and weight gain during a subsequent $3 \mathrm{~d}$ follow-up period in 

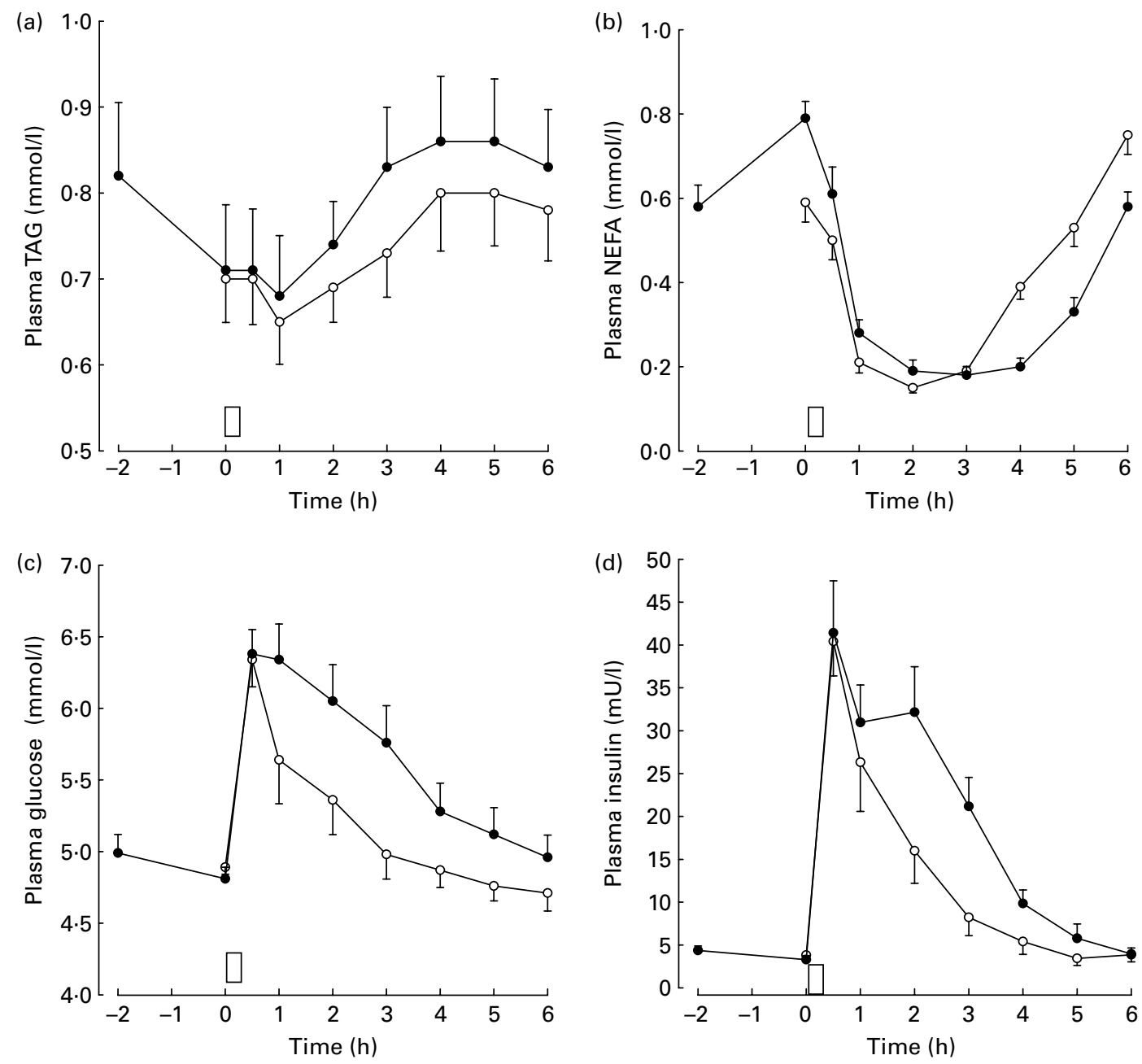

Fig. 4. Postprandial plasma TAG (a), NEFA (b), glucose (c) and insulin (d) responses during the low energy turnover $(O)$ and high energy turnover $(\bullet)$ trials. The time at which the test meal $(\square)$ was provided is shown. Values are means, with standard errors represented by vertical bars.

a cross-sectional study of 112 men and women. Furthermore, over the longer term, Eckel et al. reported that individuals who achieved more positive carbohydrate balances when consuming a high-carbohydrate diet whilst inactive gained less weight and less fat over the subsequent 4 years, suggesting that carbohydrate balance plays a strong metabolic role in long-term weight maintenance ${ }^{(45)}$. Thus, taking the present and previously reported findings ${ }^{(44,45)}$ together, it is not

Table 3. Time-averaged postprandial area under the curve values for subjective ratings of appetite $(n 13)$

(Mean values with their standard errors)

\begin{tabular}{|c|c|c|c|c|c|}
\hline & \multicolumn{2}{|c|}{$\begin{array}{l}\text { Low energy } \\
\text { turnover }\end{array}$} & \multicolumn{2}{|c|}{$\begin{array}{l}\text { High energy } \\
\text { turnover }\end{array}$} & \multirow[b]{2}{*}{$P$} \\
\hline & Mean & SEM & Mean & SEM & \\
\hline Hunger (mm) & $53 \cdot 2$ & $4 \cdot 1$ & $50 \cdot 3$ & $4 \cdot 8$ & 0.461 \\
\hline Satiety $(\mathrm{mm})$ & 39.6 & 3.4 & $44 \cdot 2$ & $4 \cdot 1$ & 0.147 \\
\hline Fullness $(\mathrm{mm})$ & 37.5 & 4.0 & 39.9 & $4 \cdot 2$ & 0.283 \\
\hline $\mathrm{PFC}(\mathrm{mm})$ & $61 \cdot 1$ & 3.1 & $58 \cdot 1$ & 4.4 & 0.279 \\
\hline Desire $(\mathrm{mm})$ & 54.9 & 3.8 & $50 \cdot 8$ & $4 \cdot 7$ & 0.138 \\
\hline
\end{tabular}

PFC, prospective food consumption. unreasonable to hypothesise that the enhanced ability of regular exercisers to maintain a healthy body weight may be due, in part, to the more positive carbohydrate balance induced by high energy turnover, leading to a reduction in relative energy intake. It is, however, important to exert a note of caution at this point. The present study was short term and did not measure participants' energy intakes after they left the laboratory, so it is not known whether or not compensatory changes to energy intake might occur over a longer time-frame. Thus, further longer-term studies are needed to confirm the present observations before firm conclusions can be reached about the role of exercise-induced alterations in carbohydrate balance in long-term weight maintenance.

The more positive carbohydrate balance in the high energy turnover trial implies higher muscle and/or liver glycogen stores. It is well established that muscle glycogen and liver resynthesis is enhanced in the hours immediately post-exercise $^{(46,47)}$ and that during this time there is increased partitioning of ingested carbohydrate towards glycogen resynthesis rather than oxidation ${ }^{(48)}$. Thus, despite carbohydrate intake at breakfast being about $65 \%$ higher in the high energy turnover trial than the low energy turnover trial (about $96 \mathrm{~g} v$. about $58 \mathrm{~g}$ of carbohydrate ingested), and 

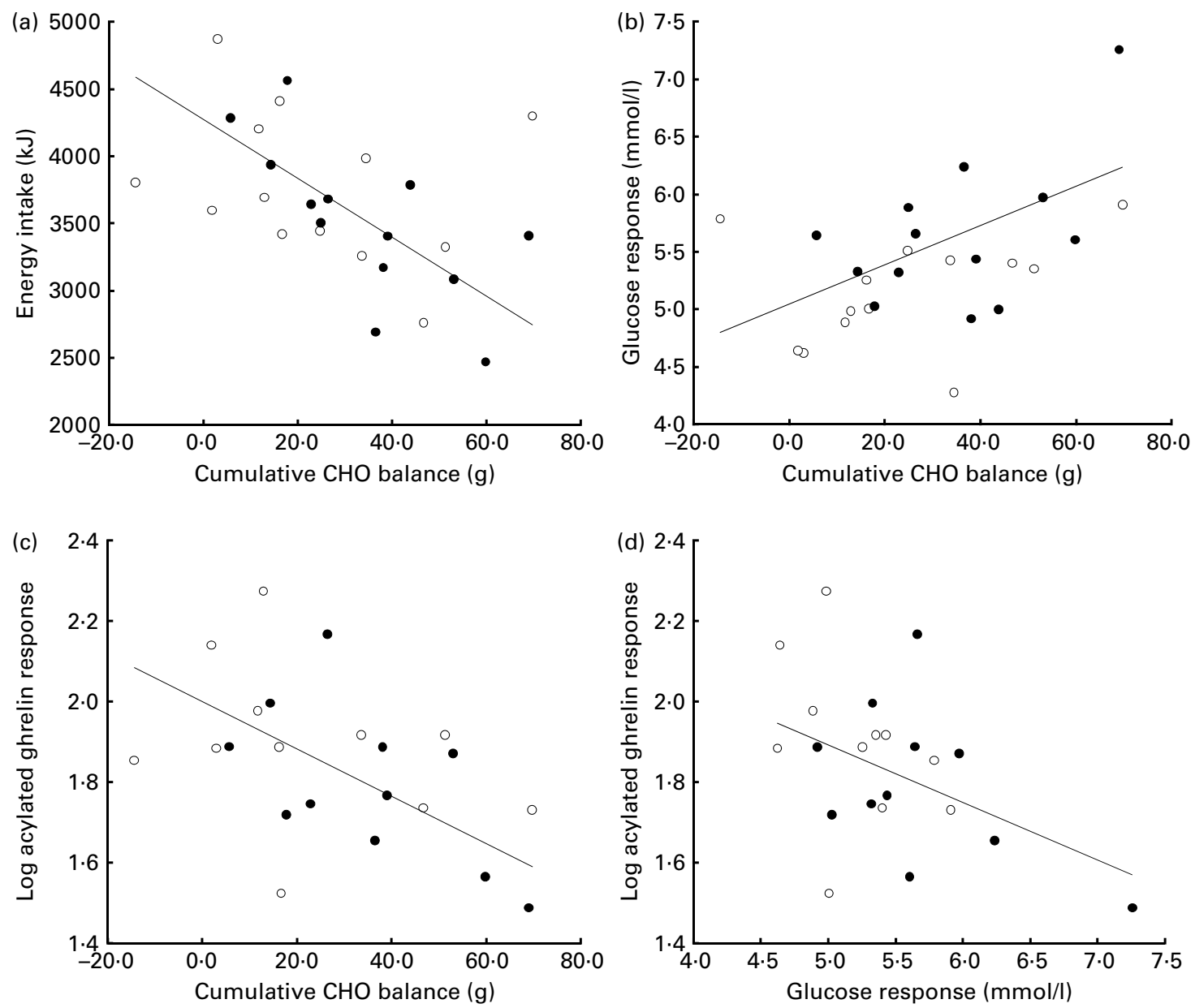

Fig. 5. Scattergrams indicating the relationship between cumulative carbohydrate $(\mathrm{CHO})$ balance and energy intake $(r-0.49$; $P=0.01)(a)$, cumulative $\mathrm{CHO}$ balance and postprandial glucose responses $(r 0.49 ; P=0.01)(b)$, cumulative $\mathrm{CHO}$ balance and log acylated ghrelin responses $(r-0.48$; $P=0.02)(\mathrm{c})$ and postprandial glucose responses and log acylated ghrelin responses $(r-0.48 ; P=0.02)(\mathrm{d})$ in the low energy turnover $(O)$ and high energy turnover $(\bullet)$ trials.

higher postprandial glucose concentrations in the high energy turnover trial, carbohydrate oxidation over the postprandial observation period did not differ between trials. This is in contrast to situations when carbohydrate intake is increased in the absence of prior exercise, which results in a marked increase in carbohydrate oxidation ${ }^{(49)}$.

One interesting observation in the present study is that ad libitum food consumption at the buffet meal led to identical levels of carbohydrate balance in the low and high energy turnover trials on completion of the meal, suggesting that individuals ate until a 'set point' for carbohydrate balance was achieved. This fits well with observations of Flatt who, more than 20 years ago, reported that, in mice, energy intake was strongly related to the previous day's carbohydrate balance and proposed that, in contrast to fat stores, carbohydrate stores in the body were tightly regulated ${ }^{(50)}$. More recent studies manipulating glycogen stores in human subjects have had mixed results. Snitker et al. found that in normal-weight young white men ad libitum energy intake was inversely related to carbohydrate balance on the previous day, with carbohydrate balance explaining $9 \%$ of the variance in energy intake ${ }^{(51)}$. In contrast, carbohydrate balance explained about $24 \%$ of the variance in energy intake and $30 \%$ of the variance in carbohydrate intake in the present study. However, in the earlier report ad libitum food intake was approximately twice as high as energy expenditure $(>20 \mathrm{MJ} / \mathrm{d}$ and about $10 \mathrm{MJ} / \mathrm{d})^{(51)}$, suggesting that other external factors, such as availability of large quantities of highly palatable food, may have led to hedonic factors over-riding endogenous homeostatic appetite signals ${ }^{(52)}$. Shetty et al. reported that manipulating carbohydrate balance by altering the carbohydrate content of the diet did not influence energy intake, but in the present study the achieved differences in carbohydrate balances between diets were only about a third of the difference in carbohydrate intake due to autoregulatory changes to carbohydrate oxidation ${ }^{(53)}$. In contrast, the increased carbohydrate intake in the high energy turnover trial in the present study did not lead to increased carbohydrate oxidation. Thus, the scenario of high $v$. low energy turnover appears to influence substrate metabolism and subsequent energy intake differently from the manipulation of carbohydrate balance by altering the composition of isoenergetic diets.

Studies which have investigated the effects of an exercise session on circulating acylated ghrelin in adults have reported decreases in concentration of the hormone during and immediately following exercise ${ }^{(25,27,28)}$ but the effects on acylated ghrelin concentrations during the hours following an exercise session are less clear ${ }^{(25,27)}$. The present data demonstrate that 
when energy intake is increased to maintain energy balance, the exercise-induced attenuation in acylated ghrelin concentrations persists for at least $6 \mathrm{~h}$. Interestingly, however, this occurred without any difference in subjective ratings of appetite between trials although the ghrelin response was associated significantly with carbohydrate balance, which, in turn, was strongly associated with energy intake. While it is possible that the VAS questionnaires used in the present study had insufficient power to detect subtle differences in appetite sensations, the present data may indicate that any potential role of acylated ghrelin in the regulation of feeding behaviour was not occurring at an overtly conscious level. Furthermore, the finding that questionnaires could not detect differences in sensations of appetite between the two trials, despite clear differences in energy balance being evident after the buffet meal, highlights the importance of using direct measures of food consumption, and not relying on reported sensations of appetite, in studies attempting to elucidate the effects of exercise on energy balance and feeding behaviour.

Although not definitive on this issue, our data may help elucidate the 'signal' which relates carbohydrate balance to appetite. Glucose and acylated ghrelin responses both correlated significantly with carbohydrate balance, and with each other, and glucose concentrations were significantly higher, and acylated ghrelin concentrations significantly lower, in the high energy turnover trial than the low energy turnover trial. Evidence from the literature suggests that it is likely that blood glucose concentration plays a role in the regulation of appetite. Spontaneous meal ingestion synchronises well with transient declines in blood glucose concentration ${ }^{(54)}$, and glucose infusion has been shown to suppress food intake $^{(55)}$ and increase satiety ${ }^{(56)}$. In addition, it has been reported that energy intake at an ad libitum meal was significantly negatively correlated with the plasma glucose response to carbohydrate pre-load ${ }^{(57)}$, which is in broad agreement with the present study, although the relationship between the plasma glucose response and energy intake at the buffet meal did not quite achieve statistical significance in the present trial $(r-0 \cdot 36 ; P=0 \cdot 068)$. It is conceivable that the effects of plasma glucose on appetite regulation and food intake could have been mediated via acylated ghrelin, as glucose has been shown to modulate ghrelin secretion ${ }^{(58-60)}$; however, the evidence for this playing a major role in the present study is not particularly strong. While the acylated ghrelin response was lower in the high energy turnover trial, and correlated significantly with carbohydrate balance and the glucose response, it was not related to energy intake at the buffet meal. Although it is possible that this lack of association was a consequence of low statistical power, it is also becoming evident that ghrelin itself exerts glucoregulatory effects ${ }^{(61)}$, and thus the direction of causality in the acylated ghrelin-glucose relationship in the present study cannot be definitely stated. In addition, evidence from a number of recent studies has suggested that ghrelin appears to act as a marker of energy status, rather than as a direct stimulator of energy intake ${ }^{(62,63)}$ and our data are consistent with this observation. Thus, further study is required to elucidate how carbohydrate balance and acylated ghrelin and glucose concentrations interact to regulate feeding behaviour under low and high energy turnover conditions.

In conclusion, our findings demonstrate that energy balance under high energy turnover conditions is metabolically different from energy balance under low energy turnover conditions, resulting in a more positive carbohydrate balance. This, in turn, was associated with reduced subsequent ad libitum energy intake. Thus, the present findings provide insight into a potential mechanism by which exercise influences appetite and feeding behaviour, although further study is needed to determine whether these observations extend over the longer term.

\section{Acknowledgements}

We thank Dr Nicholas Barwell and Dr Lesley Hall for their clinical assistance with subject screening and on experimental study days and Mrs Heather Collin for technical support.

This project received no external funding.

F. L. B. and J. M. R. G. designed the study, F. L. B. was responsible for data collection under the supervision of J. M. R. G., and all authors contributed to data analysis and interpretation, and writing the manuscript.

The authors have no conflicts of interest relevant to this paper.

\section{References}

1. Wareham NJ, van Sluijs EMF \& Ekelund U (2005) Physical activity and obesity prevention: a review of the current evidence. Proc Nutr Soc 64, 229-247.

2. Saris WH, Blair SN, van Baak MA, et al. (2003) How much physical activity is enough to prevent unhealthy weight gain? Outcome of the IASO 1st Stock Conference and consensus statement. Obes Rev 4, 101-114.

3. Jeffery RW, Wing RR, Sherwood NE, et al. (2003) Physical activity and weight loss: does prescribing higher physical activity goals improve outcome? Am J Clin Nutr 78, 684-689.

4. Schoeller DA (1998) Balancing energy expenditure and body weight. Am J Clin Nutr 68, 956S-961S.

5. Votruba SB, Atkinson RL, Hirvonen MD, et al. (2002) Prior exercise increases subsequent utilization of dietary fat. Med Sci Sports Exerc 34, 1757-1765.

6. Votruba SB, Atkinson RL \& Schoeller DA (2003) Prior exercise increases dietary oleate, but not palmitate oxidation. Obes Res 11, 1509-1518.

7. Hansen K, Shriver T \& Schoeller D (2005) The effects of exercise on the storage and oxidation of dietary fat. Sports Med 35, 363-373.

8. Gill JMR, Frayn KN, Wootton SA, et al. (2001) Effect of prior moderate exercise on exogenous and endogenous lipid metabolism and plasma factor VII activity. Clin Sci 100, 517-527.

9. Melanson EL, MacLean PS \& Hill JO (2009) Exercise improves fat metabolism in muscle but does not increase 24-h fat oxidation. Exerc Sport Sci Rev 37, 93-101.

10. Seidell JC, Muller DC, Sorkin JD, et al. (1992) Fasting respiratory exchange ratio and resting metabolic rate as predictors of weight gain: the Baltimore Longitudinal Study on Aging. Int J Obes Relat Metab Disord 16, 667-674.

11. Marra M, Scalfi L, Covino A, et al. (1998) Fasting respiratory quotient as a predictor of weight changes in non-obese women. Int J Obes Relat Metab Disord 22, 601-603.

12. Zurlo F, Lillioja S, Esposito-Del Puente A, et al. (1990) Low ratio of fat to carbohydrate oxidation as predictor of weight gain: study of 24-h RQ. Am J Physiol 259, E650-E657.

13. George VA \& Morganstein A (2003) Effect of moderate intensity exercise on acute energy intake in normal and overweight females. Appetite 40, 43-46. 
14. Hubert P, King NA \& Blundell JE (1998) Uncoupling the effects of energy expenditure and energy intake: appetite response to short-term energy deficit induced by meal omission and physical activity. Appetite 31, 9-19.

15. Imbeault P, Saint-Pierre S, Almeras N, et al. (1997) Acute effects of exercise on energy intake and feeding behaviour. Br J Nutr 77, 511-521.

16. King NA, Lluch A, Stubbs RJ, et al. (1997) High dose exercise does not increase hunger or energy intake in free living males. Eur J Clin Nutr 51, 478-483.

17. Martins C, Morgan LM, Bloom SR, et al. (2007) Effects of exercise on gut peptides, energy intake and appetite. $J$ Endocrinol 193, 251-258.

18. Stubbs RJ, Sepp A, Hughes DA, et al. (2002) The effect of graded levels of exercise on energy intake and balance in free-living women. Int J Obes Relat Metab Disord 26, 866-869.

19. Pomerleau M, Imbeault P, Parker T, et al. (2004) Effects of exercise intensity on food intake and appetite in women. Am J Clin Nutr 80, 1230-1236.

20. Westerterp-Plantenga MS, Verwegen CR, Ijedema MJ, et al. (1997) Acute effects of exercise or sauna on appetite in obese and nonobese men. Physiol Behav 62, 1345-1354.

21. Stubbs RJ, Hughes DA, Johnstone AM, et al. (2004) Rate and extent of compensatory changes in energy intake and expenditure in response to altered exercise and diet composition in humans. Am J Physiol Regul Integr Comp Physiol 286, R350-R358.

22. Burns SF, Broom DR, Miyashita M, et al. (2007) A single session of treadmill running has no effect on plasma total ghrelin concentrations. J Sports Sci 25, 635-642.

23. Jurimae J, Hofmann P, Jurimae T, et al. (2007) Plasma ghrelin responses to acute sculling exercises in elite male rowers. Eur $J$ Appl Physiol 99, 467-474.

24. Kraemer RR, Durand RJ, Acevedo EO, et al. (2004) Rigorous running increases growth hormone and insulin-like growth factor-I without altering ghrelin. Exp Biol Med (Maywood) 229, 240-246.

25. Broom DR, Stensel DJ, Bishop NC, et al. (2007) Exerciseinduced suppression of acylated ghrelin in humans. $J$ Appl Physiol 102, 2165-2171.

26. Mackelvie KJ, Meneilly GS, Elahi D, et al. (2007) Regulation of appetite in lean and obese adolescents after exercise: role of acylated and desacyl ghrelin. J Clin Endocrinol Metab 92, 648-654.

27. Broom DR, Batterham RL, King JA, et al. (2009) Influence of resistance and aerobic exercise on hunger, circulating levels of acylated ghrelin, and peptide YY in healthy males. Am J Physiol Regul Integr Comp Physiol 296, R29-R35.

28. Marzullo P, Salvadori A, Brunani A, et al. (2008) Acylated ghrelin decreases during acute exercise in the lean and obese state. Clin Endocrinol (Oxf) 69, 970-971.

29. Martins C, Truby H \& Morgan LM (2007) Short-term appetite control in response to a 6-week exercise programme in sedentary volunteers. Br J Nutr 98, 834-842.

30. Long SJ, Hart K \& Morgan LM (2002) The ability of habitual exercise to influence appetite and food intake in response to high- and low-energy preloads in man. Br J Nutr 87, 517-523.

31. Burton FL, Malkova D, Caslake MJ, et al. (2008) Energy replacement attenuates the effects of prior moderate exercise on postprandial metabolism in overweight/obese men. Int $J$ Obes (Lond) 32, 481-489.

32. Balady GJ, Berra KA, Golding LA, et al. (2000) ACSM's Guidelines For Exercise Testing and Prescription, 6th ed. Philadelphia, PA: Lippincott Williams \& Wilkins.

33. Flint A, Raben A, Blundell JE, et al. (2000) Reproducibility, power and validity of visual analogue scales in assessment of appetite sensations in single test meal studies. Int $J$ Obes Relat Metab Disord 24, 38-48.
34. Shetty P (2005) Energy requirements of adults. Public Health Nutr 8, 994-1009.

35. Borg GA (1973) Perceived exertion: a note on 'history' and methods. Med Sci Sports 5, 90-93.

36. Gore CJ \& Withers RT (1990) Effect of exercise intensity and duration on postexercise metabolism. J Appl Physiol 68, 2362-2368.

37. Laforgia J, Withers RT, Shipp NJ, et al. (1997) Comparison of energy expenditure elevations after submaximal and supramaximal running. J Appl Physiol 82, 661-666.

38. Sedlock DA, Fissinger JA \& Melby CL (1989) Effect of exercise intensity and duration on postexercise energy expenditure. Med Sci Sports Exerc 21, 662-666.

39. Herman CP \& Polivy J (2005) Normative influences on food intake. Physiol Behav 86, 762-772.

40. Frayn KN (1983) Calculation of substrate oxidation rates in vivo from gaseous exchange. J Appl Physiol 55, 628-634.

41. Flatt JP, Ravussin E, Acheson KJ, et al. (1985) Effects of dietary fat on postprandial substrate oxidation and on carbohydrate and fat balances. J Clin Invest 76, 1019-1024.

42. Melanson EL, Donahoo WT, Dong F, et al. (2005) Effect of low- and high-calcium dairy-based diets on macronutrient oxidation in humans. Obes Res 13, 2102-2112.

43. Melanson EL, Sharp TA, Seagle HM, et al. (2002) Resistance and aerobic exercise have similar effects on 24-h nutrient oxidation. Med Sci Sports Exerc 34, 1793-1800.

44. Pannacciulli N, Salbe AD, Ortega E, et al. (2007) The 24-h carbohydrate oxidation rate in a human respiratory chamber predicts ad libitum food intake. Am J Clin Nutr 86, 625-632.

45. Eckel RH, Hernandez TL, Bell ML, et al. (2006) Carbohydrate balance predicts weight and fat gain in adults. Am J Clin Nutr 83, 803-808.

46. Casey A, Mann R, Banister K, et al. (2000) Effect of carbohydrate ingestion on glycogen resynthesis in human liver and skeletal muscle, measured by ${ }^{13} \mathrm{C}$ MRS. Am J Physiol Endocrinol Metab 278, E65-E75.

47. Price TB, Rothman DL, Taylor R, et al. (1994) Human muscle glycogen resynthesis after exercise: insulin-dependent and -independent phases. J Appl Physiol 76, 104-111.

48. Kiens B \& Richter EA (1998) Utilization of skeletal muscle triacylglycerol during postexercise recovery in humans. Am J Physiol 275, E332-E337.

49. Acheson KJ, Schutz Y, Bessard T, et al. (1984) Nutritional influences on lipogenesis and thermogenesis after a carbohydrate meal. Am J Physiol 246, E62-E70.

50. Flatt JP (1987) Dietary fat, carbohydrate balance, and weight maintenance: effects of exercise. Am J Clin Nutr 45, 296-306.

51. Snitker S, Larson DE, Tataranni PA, et al. (1997) Ad libitum food intake in humans after manipulation of glycogen stores. Am J Clin Nutr 65, 941-946.

52. Finlayson G, King N \& Blundell JE (2007) Liking vs. wanting food: importance for human appetite control and weight regulation. Neurosci Biobehav Rev 31, 987-1002.

53. Shetty PS, Prentice AM, Goldberg GR, et al. (1994) Alterations in fuel selection and voluntary food intake in response to isoenergetic manipulation of glycogen stores in humans. Am J Clin Nutr 60, 534-543.

54. Melanson KJ, Westerterp-Plantenga MS, Campfield LA, et al. (1999) Blood glucose and meal patterns in time-blinded males, after aspartame, carbohydrate, and fat consumption, in relation to sweetness perception. Br J Nutr 82, 437-446.

55. Chapman IM, Goble EA, Wittert GA, et al. (1998) Effect of intravenous glucose and euglycemic insulin infusions on short-term appetite and food intake. Am J Physiol 274, R596-R603.

56. Gielkens HA, Verkijk M, Lam WF, et al. (1998) Effects of hyperglycemia and hyperinsulinemia on satiety in humans. Metabolism 47, 321-324. 
57. Anderson GH, Catherine NL, Woodend DM, et al. (2002) Inverse association between the effect of carbohydrates on blood glucose and subsequent short-term food intake in young men. Am J Clin Nutr 76, 1023-1030.

58. Shiiya T, Nakazato M, Mizuta M, et al. (2002) Plasma ghrelin levels in lean and obese humans and the effect of glucose on ghrelin secretion. J Clin Endocrinol Metab 87, 240-244.

59. Greenman Y, Golani N, Gilad S, et al. (2004) Ghrelin secretion is modulated in a nutrient- and gender-specific manner. Clin Endocrinol (Oxf) 60, 382-388.

60. Cukier K, Pilichiewicz AN, Chaikomin R, et al. (2008) Effect of small intestinal glucose load on plasma ghrelin in healthy men. Am J Physiol Regul Integr Comp Physiol 295, R459-R462.

61. Pusztai P, Sarman B, Ruzicska E, et al. (2008) Ghrelin: a new peptide regulating the neurohormonal system, energy homeostasis and glucose metabolism. Diabetes Metab Res Rev 24, $343-352$.

62. Scrimgeour K, Gresham MJ, Giles LR, et al. (2008) Ghrelin secretion is more closely aligned to energy balance than with feeding behaviour in the grower pig. $J$ Endocrinol 198, 135-145.

63. Borer KT, Wuorinen E, Ku K, et al. (2009) Appetite responds to changes in meal content, whereas ghrelin, leptin, and insulin track changes in energy availability. J Clin Endocrinol Metab 94, 2290-2298. 